\title{
Parkinsonian Syndrome as a Neurological Manifestation of Behcet's Disease
}

\author{
D. Bogdanova, I. Milanov and D. Georgiev
}

\begin{abstract}
Background: The central nervous system is often involved in Behcet's disease. Most common are meningoencephalitic and brain stem syndromes. Although basal ganglia involvement is not an uncommon finding on necropsy, there are only single reports on extrapyramidal syndromes-dyskinesia, chorea and Parkinsonism in patients with Behcet's disease. Case study: We report a patient fulfilling the criteria of the International Study Group for Behcet's disease. He had recurrent oral ulcerations, bilateral posterior uveitis and retinal vasculitis, skin papules and pustules, and recurrent monoarthritis. Neurologic examination revealed pseudobulbar palsy, slight and asymmetric bilateral pyramidal syndrome, muscle rigidity involving the four limbs, bradykinesia, masked face, and impaired postural reflexes. There was postural tremor in the extremities and myoclonic jerks involving the tongue and face muscles. Magnetic resonance imaging demonstrated small bilateral multifocal hyperintense lesions, with right predilection, involving the periventricular white matter, brain stem and basal ganglia. Conclusions: The Parkinsonian syndrome found in our patient might be due to involvement of both substantia nigra and basal ganglia. This case further emphasizes the wide spectrum of the neurological manifestations of Behcet's disease
\end{abstract}

\begin{abstract}
RÉSUMÉ: Syndrome parkinsonien comme manifestation neurologique de la maladie de Behçet - À propos d'un cas. Introduction: Le système nerveux central est souvent aatteint dans la maladie de Behçet les manifestations les plus fréquentes étant un syndrome méningoencéphalitique et une atteinte du tronc cérébral. Bien qu'il ne soit pas exceptionnel de trouver une atteinte du noyau lenticulaire, du noyau caudé, de l'avant-mur et du noyau amygdalien à l'autopsie, il y a peu de cas rapportés de syndromes extrapyramidaux-dyskinésies, chorée et parkinsonisme chez les patients atteints de la maladie de Behçet. Étude de cas: Nous rapportons le cas d'un patient qui remplissait les critères du Groupe international d'étude sur la maladie de Behçet. Il avait des ulcères buccaux récurrents, une uvéite postérieure bilatérale et une vasculite rétinienne, des papules et des pustules cutanées et une monoarthrite récurrente. L'examen neurologique a montré une paralysie pseudobulbaire, un léger syndrome pyramidal asymétrique bilatéral, une rigidité musculaire impliquant les quatre membres, une bradykinésie, un faciès parkinsonien et des réflexes posturaux perturbés. Il avait en outre un tremblement postural des extrémités et des secousses myocloniques de la langue et des muscles du visage. La résonance magnétique a montré de petites lésions hyperintenses multifocales et bilatérales, surtout à droite, impliquant la substance blanche périventriculaire, le tronc cérébral et les noyaux lenticulaire, caudé et amygdalien ainsi que l'avantmur. Conclusions: Le syndrome parkinsonien observé chez notre patient pourrait être dû à l'atteinte de la substance noire et des noyaux lenticulaire, caudé et amygdalien ainsi que de l'avant-mur. Ce cas démontre le spectre étendu des manifestations neurologiques de la maladie de Behçet.
\end{abstract}

Can. J. Neurol. Sci. 1998; 25: 82-85

Behcet's disease is a world-wide disease, more common in the Middle-East and Eastern Mediterranean. ${ }^{1}$ It was first described by Behcet in 1937, as a triad of aphthous stomatitis, genital ulceration and uveitis. ${ }^{1}$ It is a chronic recurrent multisystem disease, now considered as a systemic vasculitis of unknown etiology. ${ }^{2,3}$ It affects the skin, joints, eyes, gastrointestinal tract, blood vessels and nervous system. ${ }^{4}$

Neurological involvement is found in $5.3 \%$ to $28 \%$ of the patients. ${ }^{5.6}$ Male prevalence is predominant in the more severe neuro-Behcet. ${ }^{6,7}$ It may occur mainly in two ways: primary (parenchymal) - neuro-Behcet, or secondary to major vascular events-vasculo-Behcet. ${ }^{5,8,9}$ The neurologic symptoms usually have an abrupt onset, tendency to remit and relapse and a poor prognosis. ${ }^{7}$

The neurological manifestations are variable, including septic meningitis, brainstem and diencephalon syndromes, pyrami- dal quadriparesis with pseudobulbar palsy, intracranial hypertension and medullary syndrome. ${ }^{2.10}$ Although basal ganglia involvement is not an uncommon finding on necropsy, ${ }^{11}$ there are only single reports on extrapyramidal syndromes such as dyskinesia, ${ }^{12}$ chorea ${ }^{13}$ and undefined "extrapyramidal lesion"4 in patients with Behcet's disease. The existence of Parkinsonianlike syndromes has been only mentioned. ${ }^{11,14}$

\section{Case Report:}

A 20-year-old man was admitted to the clinic in March 1996 due to acute attack of dysarthria, dysphagia, hands, legs and tongue tremor,

From the University Hospital for Neurology and Psychiatry-IV kilometre, Sofia, III Neurological Clinic.

RECEIVED FEBRUARY 13, 1997. ACCEPTED IN FINAL, FORM AUGUST 8, 1997.

Reprint requests to: D. Bogdanova, MD, University Neurological Hospital, Tzarigradsko shosse BIvd. IV kilometre, 1113, Sofia. Bulgaria 
delay in initiation of movements, difficulty in walking and arising from sitting to standing, masked face with neither smiling nor blinking, loss of normal arm swinging when walking, a simian-like posture with flexion of all joints (ankles, knees, hips, back and neck) increased salivation, gait impairment with short and shuffling steps, apathy and inversion of sleep patterns (insomnia and daytime somnolence). He was in good health until October 1995 when he started complaining of blurred vision in the right eye, diagnosed by an ophthalmologist as serofibrinous posterior uveitis and exudative ablation of the retina. In November 1995 he noticed impairment of the speech; CT brain scan exam was normal. One month later in December 1995, blurred vision in the uninvolved eye appeared and a posterior uveitis and ablation of the retina in the left eye was confirmed by an ophthalmologist.

His past medical history included recurrent oral aphthous stomatitis, skin papules and pustules, and recurrent monoarthritis in right knee joint.

Physical examination showed aphtous stomatitis on the buccal mucosa. The lingual mucosa was covered with yellowish patches. He had inflammed pustular lesions on his face, neck and back and monoarthritis involving the right knee joint. The lungs were clear, cardiovascular exanı was unremarkable, there was no hepatosplenomegaly and renal function was normal.

Ophthalmological examination disclosed bilateral posterior uveitis and retinal valsculitis. Visual activity was down to light perception in both eyes.

Neurologic examination revealed pseudobulbar palsy with dysarthria, dysphonia, positive snout, suck and palmomental reflexes and pathologically brisk jaw jerk. Slight and asymmetric bilateral pyramidal syndrome with brisk tendon reflexes predominantly in the left limbs, and left Babinski sign were evident. Muscle strength was preserved and there was no spastically increased muscle tone with claspknife phenomenon. Muscle lead pipe rigidity involving the four limbs with cogwheel phenomenon in the wrists, bradykinesia, masked face with loss of facial expression and impaired postural reflexes were found. There was loss of normal arm-swinging when walking, and when turning, balance was uncertain. There was gradual reduction in the size and legibility of his handwriting (micrographia). There was postural tremor in the extremities and myoclonic jerks involving the tongue and face muscles. The patient was in an apathetic state.

Liboratory examinations revealed normal haemoglobin, red and white blood cells, platelet and differential count, erythrocyte sedimentation rate, liver and kidney function tests and serum electrolytes. Blood glucose, prothrombin time, partial thromboplastin time, fibrinogen, serum protein and $\mathrm{C}$-reactive protein were within normal limits. Serum immunoglobulins $\operatorname{lgG}, \lg$ A, IgM, C3, C4, C9 were within normal limits. The titre of cryoprecipitates was increased, the ratio T4:T8 was normal, circulating immune complexes were within normal limits, antibody reactions against human mucosal tissue and antinuclear antibodies to ssDNA, dsDNA were positive, while reactions to RNP were negative. Cardiolipin antibodies examined by ELISA were positive (IgG-24 GPU, IgM-80 MPU). Serologic tests for syphilis, toxoplasmosis and neuroboreliosis were negative. Anti-HIV antibodies were not present.

Cerebro-spinal fluid (CSF) characteristics were: normal pressure, proteins $75 \mathrm{mg} / \mathrm{dl}$, lymphocytes $112.10^{6} /$. Electrophoretic examination was normal. The pathergy test was non-reactive at 48 hours. On haplotype analysis the patient expressed HLA B5 and HLA B27.

EMG findings confirmed the presence of myoclonic jerks of about 3 $\mathrm{H} z$ frequency. The EMG examination also revealed postural tremor with $12 \mathrm{~Hz}$ frequency and synchronous pattern in antagonistic muscles. EEG showed increased slow waves and disorganization of the background activity.

Magnetic resonance imaging (MRI) T2/ISE and TSE/DUAL demonstrated small bilateral multifocal hyperintense lesions with predilection in right in periventricular white matter, brain stem and basal ganglia (Figures 1 and 2).

The patient was treated by pulsed megadose steroids: $1000 \mathrm{mg}$ of intravenous methylprednisolone and $1000 \mathrm{mg}$ intravenous cyclophosphamide, both once a month and oral colchicine $1.5 \mathrm{mg}$ daily. Antiparkinsonian therapy with Sinemet $\$ 750 \mathrm{mg}$ daily was applied. No clinical improvement was achieved.

\section{Discussion}

There are no specific laboratory or neuroimaging abnormalities in Behcet's disease and the diagnosis is made essentially on clinical grounds. The diagnosis in our case was made on the criteria of the International Study Group for Behcet's Disease: ${ }^{15}$ there were recurrent oral ulcerations, appearing three times in a six month period, observed by the patient and the physician; eye lesions (bilateral posterior uveitis and retinal vasculitis) observed by ophthalmologist and skin lesions (papulo-pustular) observed by physician before the corticosteroid treatment. The symptomatic triad is often not complete. ${ }^{11}$ Our patient had no recurrent genital ulcerations, which may be absent in nearly half of the patients." The pathergy test was negative, but in spite of this the diagnostic criteria were fulfilled.

The real problem in diagnosis of Bencet's disease is differentiating from other forms of vasculitis such as systemic lupus erythematodes (SLE), which can produce oral ulcerations and iritis as well central nervous system involvement. ${ }^{14}$ Although anti - ds DNA antibodies are typically seen in SLE, low titers

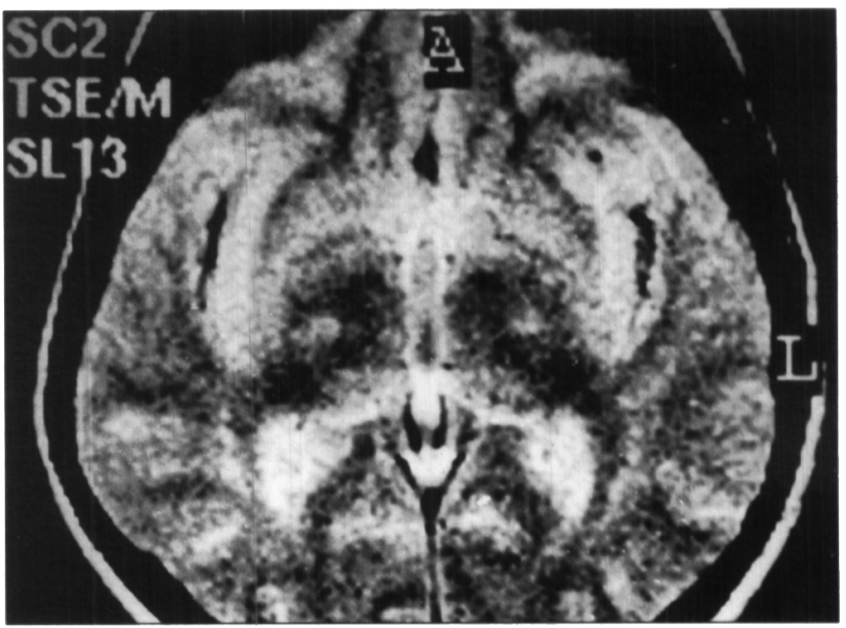

Figure 1: Magnetic resonance imaging T2/ISE and TSE/DUAL demonstrating hyperintense lesions in the basal ganglia.

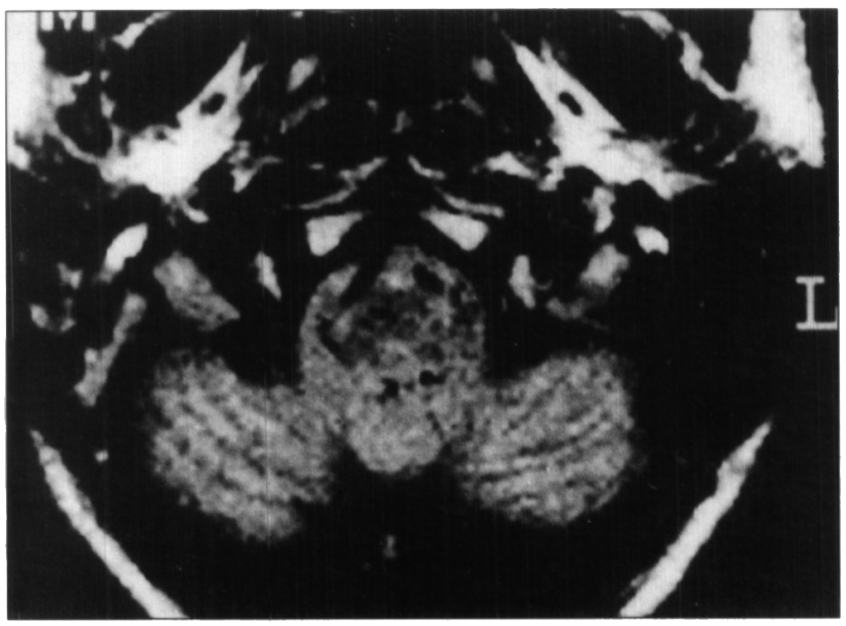

Figure 2: Magnetic resonance imaging T2/ISE and TSE/DUAL demonstrating multifocal hyperintense brain stem lesions. 
have also been demonstrated in the sera of patients with other connective tissue diseases. ${ }^{16}$ Our patient had oral ulcerations, an abnormal titer of antinuclear antibodies and anti-ds DNA antibodies, but had no malar or discoid rush, photosensitivity, polyarthritis, serositis, renal disorder, hematologic disorder, seizures or psychosis, and so did not fulfill the requirement of the American Rheumatism Association for 4 of the 11 criteria for SLE. ${ }^{16}$

Neurological involvement in Behcet's disease usually begins with a definite acute attack ${ }^{7}$ and the differential diagnosis with multiple sclerosis may be difficult on purely clinical grounds. ${ }^{10}$ Some MRI findings are in favour of Behcet's disease: involvement of basal ganglia, thalamus, central part of pons, and absence of periventricular predominance in white matter lesions. ${ }^{17}$ Lesions of the brain stem are consistently associated with severe neurological impairment such as tetraparesis and pseudobulbar palsy. ${ }^{17}$ The MRI abnormalities are not specific and can be observed in other central nervous system vasculitis; however, the brain stem involvement is rarely found in SLE. Cerebro-spinal fluid examination might be normal, ${ }^{7}$ or reveal slight lymphocytosis and mild elevation of protein, ${ }^{18}$ as in our patient. However the electrophoretic examination is usually normal in contrast to multiple sclerosis. ${ }^{3}$ High levels of intracranial pressure, high protein content and/or pleocytosis usually predict a poor prognosis. ${ }^{7}$ Although there are no specific laboratory investigations, an elevated sedimentation rate, $\mathrm{C}$-reactive protein and serum $\lg A, \operatorname{lgG}, \operatorname{lgM}$, and/or $\mathrm{C} 9$ levels have been reported. ${ }^{19}$ Elevated cerebro-spinal fluid IgM, IgG and IgA, and C3 and $\mathrm{C} 4$ concentrations have been reported, ${ }^{20}$ although in our case they were normal. Circulating immune complexes and autoantibodies to mucosal tissue and a decreased proportion of helper/inducer T4 lymphocytes have also been reported. ${ }^{9,19}$ Our investigations revealed antibodies to human mucosal tissue, antinuclear antibodies and increased cryoprecipitates, while indices of circulating immune complexes, the third (C3) and the fourth (C4) components of complement and the T helpers/inducers ratio were within normal limits. Anticardiolipin antibodies (ACA) have been found in some patients with Behcet's disease, and are clearly associated with thrombosis at multiple sites. ${ }^{21.22}$ ACA antibodies IgG and IgM were positive in our case. It is known that HLA B5 is related to the ocular type, HLA B27 to the arthritic type, and HLA B12 to the mucocutaneous type of Behcet's disease in some populations. ${ }^{19}$ The reported patient with ocular, arthritic and mucocutaneous symptoms was positive for HLA B5 and HLA B27.

The patient presented here has all the previously described main features of Behcet's disease. The neurologic involvement was extremely severe, despite the short course of the disease. Brain stem involvement is reported to be the most common and disabling manifestation of neuro-Behcet's syndrome. ${ }^{6}$ Bilateral pyramidal lesions and pseudobulbar palsy might mimic parkinsonian syndrome due to muscle weakness and lability in facial expression. Apathy also adds to lack of normal facial expression. However, our patient had a clear lead-pipe rigidity with cogwheel phenomenon, postural disturbances, flexed gait and increased salivation, while the muscle strength was preserved. The impairment of vision in both eyes further increases the patient's disability. It is noted that uveitis is more common among the patients with neurologic involvement. ${ }^{6,7}$ Generalized myoclonic jerks attributed to brain stem involvement, ${ }^{6}$ as well as diencephalic symptoms including sleep disturbances have been reported. ${ }^{2,7}$ Dyskinesia in patients with Behcet's disease due to a discrete lesion in the internal segment of the globus pallidus has been described. ${ }^{12}$ Chorea in Behcet's syndrome has also been described. ${ }^{13}$ Parkinsonian-like syndromes with rigidity and akinesia have been reported in some patients. ${ }^{11}{ }^{14}$ In one case, Parkinsonian symptoms were combined with intention tremor. ${ }^{14}$ We were not able to find a report on patients with typical static Parkinsonian tremor. In our patient there was also no evidence for any static tremor. However, a postural tremor, with the characteristics of enhanced physiological tremor ${ }^{23}$ was found. Such tremor may sometimes be present in Parkinsonian patients, even without any static tremor. ${ }^{24}$ In patients with Behcet's disease, foci of necrosis in the substantia nigra, ${ }^{25}$ and basal ganglia have been found on necropsy." "Both gray and white matter are usually involved and microglial infiltration of the gray matter has usually been observed. ${ }^{11}$ Thus the Parkinsonian syndrome found in our patient might be due to involvement of both substantia nigra, and basal ganglia. However, the lack of improvement after levodopa therapy suggests predominantly basal ganglia involvement. Our patient had no improvement from treatment with high doses of corticosteroids and immunosuppresive agents, probably because of the multiple and severe involvement.

The presented case has a rare combination of all the main features of Behcet's disease and Parkinsonian syndrome. Bradykinesia, muscle rigidity and impaired postural reflexes were the most predominant features. No typical static tremor presented. We were not able to find any publication on typical Parkinsonian syndrome in patients with Behcet's disease. This case further emphasizes the wide spectrum of the neurological manifestations of Behcet's disease.

\section{REFERENCES}

1. Behcet $H$. Uber rezidivierende aphtose durch ein Virus verursachte Geschwure am Mund am Auge und den Genitalien. Derm Wochenschr 1937; 36: 1152-1157.

2. O'Duffy JD, Goldstein NP. Neurologic involvement in seven patients with Behcet's disease. Am J Med 1976; 6I: 170-178.

3. O'Duffy JD. Vasculitis in Behcet's disease. Rheum Clin North Am Vasculitic Syndromes 1990; 16: 423-432.

4. Chajek T, Fainaru M. Behcet's disease. Report of 41 cases and a review of the literature. Medicine 1975; 54: 179-196.

5. Wechsler B, Vidailhet M, Piette JC, et al. Cerebral venous thrombosis in Behcet's disease. Neurology 1992; 42: 614-618.

6. Serdaroglu P, Yazici H, Ozdemir C, et al. Neurological involvement in Behcet's syndrome. Arch Neurol 1989; 46: 265-269.

7. Akman-Demir G, Baycan-Kurt B, Serdaroglu P, et al. Seven-year follow-up of neurologic involvement in Behcet syndrome. Arch Neurol 1996; 53: 691-694.

8. Akman-Demir G, Bahar S, Baycan-Kurt B, Gurvit HI, Serdaroglu P. Intracranial hypertension in Behcet's disease. Eur J Neurol 1996; 3: 66-70.

9. Bahar S, Coban O, Gurvit H, Akman-Demir G, Gokyigit A. Spontaneous dissection of the extracranial vertebral artery with spinal subarachnoid haemorrage in a patient with Behcet's syndrome. Neuroradiology 1993; 35: 352-354.

10. Gulsen F, Akman-Demir G, Eraksoy M, et al. Paroxysmal dysarthria and ataxia in a patient with Behcet's disease. J Neurol 1995; 242: 344-347.

11. Alema G, Bignami A. Involvement of the nervous system in Behcet's disease. In: Monacelli M, Nazarro P, eds. Behcet's Disease. Proceedings of International Symposium on Behcet's Disease, Rome. Basel / New York: Karger, 1966: 52-66. 
12. Terao $Y$, Hayashi $H$, Shimizu $T$, et al. Altered motorcortical excitability to magnetic stimulation in a patient with a lesion in globus pallidus. J Neurol Sci 1995; 129(2): 175-178.

13. Bussone G, La Mantia L, Boiardi A, Giovannini P. Chorea in Behcet's syndrome. J Neurol 1982; 227(2): 89-92.

14. Hughes RAC, Lehner T. Neurological aspects of Behcet's syndrome. In: Lehner T, Barnes, CG, eds. Behcet's Syndrome. Clinical and Immunological Features. Proceedings of a conference. London: Academic Press Ins, 1979: 13-33.

15. International Study Group for Behcet's disease. Criteria for diagnosis of Behcet's disease. Lancet 1990; 335: 1078-1080.

16. Tan E, Cohen A, Fries J, et al. The 1982 Revised Criteria for the classification of Systemic Lupus Erythematosus. Arthritis Rheum, vol. 25, NII (Nov. 1982).

17. Wechsler B, Dell'Isola B, Vidailhet $M$, et al. MRI in 31 patients with Behcet's disease and neurological involvement: prospective study with clinical correlation. J Neurol Neurosurg Psychiatry 1993; 56(7): 793-798.

18. Miller D. Neurologic manifestations of collagen-vascular disease. In: Asbury A, McDonald W, McKhann G, eds. Diseases of the Nervous System. Clinical Neurobiology. Philadelphia: W.B. Saunders Company, 1993: 1480-1481.
19. Lehner T, Batchelor JR. Classification and an immunogenetic basis of Behcet's syndrome. In: Lehner T, Barnes CS, eds. Behcet's Syndrome. Clinical and Immunological features. Proceedings of a conference. London: Academic Press Ins, 1979: 241-259.

20. Jongen PJ, Daelmans HE, Bruneel B, Den Hartog MR. Humoral and cellular immunologic study of cerebrospinal fluid in a patient with Behcet encephalitis. Arch Neurol 1992; 49(10): 1075-1078.

21. Klok AM, Geertzen R, Rothova A, Baarsma GS, Kijlstra A. Anticardiolipin antibodies in uveitis. Curr Eye Res 1992; Suppl 11: 209-213.

22. Boggild MD, Sedhev RV, Fraser D, Heron JR. Cerebral venous thrombosis and antiphospholipid antibodies. Postgrad Med J 1995; 71(838): 487-489.

23. Elble RJ. Physiologic and essential tremor. Neurology 1986; 36 : 225-231.

24. Hadar U, Rose FC. Is Parkinsonian arm tremor a resting tremor? Eur Neurol 1993; 33: 221-228.

25. Berlin C. Behcet's syndrome with involvement of the central nervous system. Report of a case with necropsy. Arch Derm Syph (Chicago) 1944; 49: 227-233. 